\title{
Predicted Concentrations in New Relocatable Classrooms of Volatile Organic Compounds Emitted from Standard and Alternate Interior Finish Materials
}

Alfred T. Hodgson, William J. Fisk, Derek G. Shendell, and Michael G. Apte Environmental Energy Technologies Division E.O. Lawrence Berkeley National Laboratory

1 Cyclotron Road, MS 90-3058

July 18,2001

Sponsored by the California Energy Commission's Public Interest R\&D Program: High Performance Commercial Building Systems

Element 6 - Indoor Environmental Quality

Project 2.2 - Energy and IAQ Field Studies

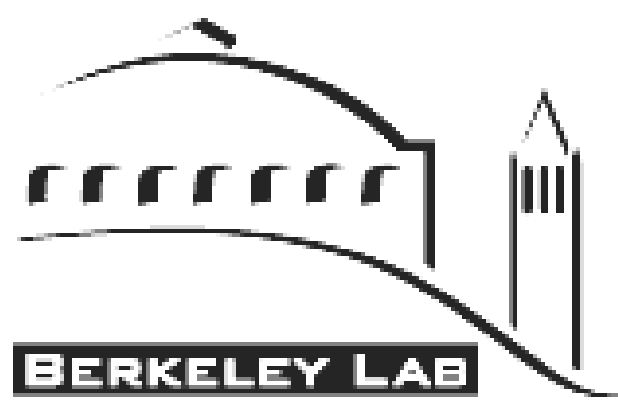




\section{Predicted Concentrations in New Relocatable Classrooms of Volatile Organic Compounds Emitted from Standard and Alternate Interior Finish Materials}

Abstract - Relocatable classrooms (RCs) are widely employed by California school districts to satisfy rapidly expanding space requirements due to population growth and class size reduction policies. There is public concern regarding indoor environmental quality (IEQ) in schools, particularly in RCs, but very little data to support or dispel these concerns. Several studies are investigating various aspects of IEQ in California schools. This laboratory-based study focused on evaluating the emissions of toxic and/or odorous volatile organic compounds (VOCs), including formaldehyde and acetaldehyde, from materials used to finish the interiors of new RCs. Furthermore, the study implemented a procedure for VOC source reduction by testing and selecting lower-emitting materials as substitutes for standard materials. In total, 17 standard and alternate floor coverings, wall panels and ceiling panels were quantitatively tested for emissions of VOCs using smallscale environmental chambers.

Working with the largest northern California manufacturer of conventional RCs and two school districts, specifications were developed for four new RCs to be produced in early summer 2001. Two of these will be predominantly finished with standard materials. Alternate carpet systems, an alternate wall panel covering and an alternate ceiling panel were selected for the two other RCs based on the results of the laboratory study and considerations of cost and anticipated performance and maintenance. Particular emphasis was placed on reducing the concentrations of VOCs on California agency lists of toxic compounds. Indoor concentrations of toxic and odorous VOCs were estimated for the four classrooms by mass balance using the measured VOC emission factors, exposed surface areas of the materials in the RCs, and three ventilation rate scenarios. Results indicate that reductions in the concentrations of formaldehyde, acetaldehyde phenol, di(ethylene glycol) butyl ether, vinyl acetate, 1,2,4-trimethylbenzene and 1-methyl-2-pyrrolidinone should be achieved as the result of the source reduction procedure.

Key Words - classroom, new construction, formaldehyde, volatile organic compounds

(VOCs), emission factor, carpet, wall panel, ceiling panel 


\section{Introduction}

Indoor environmental quality (IEQ) is one of the factors linking human performance and health with energy efficiency. During the last decade, the evidence that IEQ and related building characteristics affect health outcomes has become stronger. These health outcomes, which include sick building syndrome symptoms, allergy and asthma symptoms, and respiratory illnesses, influence rates of absence, performance of work, and health care costs. Additionally, there is growing evidence which suggests some IEQ factors, such as the thermal comfort, pollutant exposures, odors, and lighting, can directly influence human performance without having a discernable influence on health.

California public schools for grades K-12 currently enroll approximately six million students, with more than 200,000 staff. In California, the projected rapid population growth of school children and class size reduction policies makes it necessary to increase classroom space. The California Department of Education projects student enrollment in grades K-12 will increase by an average of 175,000 students per year over the next decade. The poor physical condition of many existing classrooms, and the need for seismic retrofits and internet connectivity will also force school districts to implement extensive classroom repairs, upgrades, and/or replacement programs.

Relocatable classrooms (RCs, also termed modular or portable classrooms) provide school districts with a quick, convenient and relatively low cost way to add or replace classrooms. RCs can also be moved from site to site, giving the school districts more flexibility with respect to classroom construction. Since 1986, California legislation has mandated that at least $20 \%$ of new classrooms be RCs. Unfortunately, RCs recently have become the subject of considerable public interest due to well-publicized complaints regarding IEQ. It is not currently known how RCs might differ in terms of IEQ as compared to standard site-built classrooms. However, the key factors leading to IEQ problems are the same for all building types. These factors are inadequate ventilation, elevated sources of indoor air pollutants, and poor maintenance practices.

The task reported on here focused on the evaluation of interior finish materials for RCs that may be sources of contamination by volatile organic compounds (VOCs) including formaldehyde and acetaldehyde. The objectives of this laboratory-based study 
were to: 1) characterize the current sources of VOCs of concern with respect to health and comfort; 2) identify practical low-cost procedures for reducing the classroom concentrations of these compounds, such as the substitution of lower-emitting materials; and 3) select suitable alternate materials for use in the construction of two experimental RCs to be sited at two school districts.

This task is part of a larger project to engineer and evaluate an improved RC design which simultaneously operates using less energy and provides improved IEQ as compared to the current models available on the market. Another project task is developing and demonstrating an energy efficient heating, ventilation, and air conditioning system for the same RCs. During the field study, four RCs will be constructed and placed in two school districts. One RC in each school district will be constructed using the alternative materials as discussed in this report. Energy and IEQ monitoring with detailed VOC and aldehyde measurements will be conducted over 8-10 weeks each during the cooling and heating seasons.

\section{Materials and Methods}

\section{Manufacturer selection}

Cold telephone recruitment calls were made to all of the leading RC manufacturers in California. Six manufacturers expressed willingness for Lawrence Berkeley National Laboratory (LBNL) to visit and discuss the research project and potential collaboration. In all, LBNL staff visited five RC manufacturers, including two in Southern California and three in Northern California. With the Northern California manufacturers, phone calls, on-site meetings, and tours of their production facilities were conducted in midDecember 2000. All three of these manufacturers expressed strong interest in participating. The compelling reason for their interest appeared to be the focus on VOC source reduction/material selection strategies, the potential energy use reductions and associated user cost savings, as well as the quantitative IEQ monitoring to be conducted in the subsequent field task.

Using manufacturer contacts at individual school districts, internet-based resources, and in consideration of the climate criteria for the project, 12 Northern California school 
districts (SDs) were solicited. Letters and short project descriptions were mailed to assess interest and willingness to participate. Several school districts contacted expressed a strong interest in participating. Overall, meetings with key school district staff were held in January 2001 in three potential SDs. These meetings resulted in identification of two SDs in distinct climate zones: a hot Central Valley location and a moderate transition zone (South San Francisco Bay Area) location. These schools had orders planned with one of the three selected manufacturers, American Modular Systems (AMS), for delivery in early summer 2001 for the 2001-02 school year. Subsequent discussions with all of the stakeholders for each SD (i.e., facilities manager, architect, and principals), and the approval of AMS, led to an agreement with AMS to collaborate with LBNL to supply interior finish and ventilation system modifications to RCs already on order by each SD for delivery to one of their elementary schools.

\section{Standard materials}

The RC manufacturer uses only a limited number of materials to finish the interiors of the classrooms. The materials with exposed surfaces consist primarily of glue-down carpet, resilient floor covering, tackable wall panels, ceiling panels and cabinetry. The only painted surface is door and window trim. The individual SDs establish the specifications for the floor covering materials and the quantity of cabinetry. Based on visual observations made at the other manufacturers visited, the same, or very similar, floor, wall and ceiling treatments are widely used throughout the industry. The manufacturer identified the major materials and provided samples, applicable Material Safety Data Sheets and other specifications.

\section{Alternate materials}

Cabinetry specifications from the AMS subcontractor were reviewed and material samples were inspected. LBNL concluded the cabinetry installed by the manufacturer was of high quality with all surfaces encapsulated in laminate and all counter tops with a laminate backer sheet applied to their under surface. These practices have been shown to substantially reduce the emissions of formaldehyde and other VOCs from the various engineered wood products used to form casework and countertops (Kelly, 1996; Kelly et al., 1999). Therefore, no alternate cabinetry materials were sought. 
Alternate materials with potentially lower emissions of VOCs were sought and investigated within the categories of carpet, resilient flooring, wall panels and ceiling panels. A comprehensive search of potential materials was not performed due to time and resource constraints. Instead, the selections of alternate materials were based on: 1) discussions with other practitioners (i.e., architects, designers and contractors); 2) discussions with industry representatives (i.e., manufacturers' technical service departments and sales associates); 3) online searches (e.g., Thomas Register and The Blue Book); and our own research experience. Therefore, there are more potentially acceptable alternate materials than were investigated by this project task.

\section{Collection of material samples}

The RC manufacturer provided samples of the standard materials. These were either taken from their stock or collected as scraps directly from the production facility. Samples of several of the standard materials were additionally purchased from retailers or distributors. The material manufacturers provided samples of the alternate materials, which LBNL requested be newly manufactured. In most cases, the manufacturers likely complied with this request, although there was generally no way to confirm actual production dates or sample history.

Upon receipt in the laboratory, samples of dry materials were removed from their original packaging, wrapped in two layers of aluminum foil, sealed and labeled. Adhesives were left in their original containers. The samples were then stored at room conditions until tested for emissions of VOCs. Generally, the emission tests were initiated within two weeks of receipt of the samples.

\section{Preparation of test specimens}

A test specimen was prepared from the material sample immediately prior to the initiation of the test period. Specific preparation procedures were developed for each material category.

For broadloom carpets, the objectives were to: 1) provide a representative substrate because these carpets have high permeability; and 2) seal the substrate surfaces not directly exposed when installed in the RCs. A piece of new 3/4-inch (1.9-cm) plywood 
representative of the classroom subfloor was cut into 6 by 6 -inch $(15$ by $15-\mathrm{cm})$ squares. These were wrapped together in two layers of aluminum foil, and pieces were removed from the center of the stack as needed. For glue-down carpet assemblies, adhesive was applied to one surface of a plywood square using a 3/16-inch V-notch trowel, mimicking the standard installation practice. The mass of adhesive applied was determined by weighing the plywood before and after the application. A 6 by 6 -inch square of carpet was cut from the center of the material sample and was hand pressed onto the adhesive 30 minutes after the adhesive application. The back and the four cut edges of the plywood were then covered with pieces of stainless-steel sheet metal. The sheet metal edges were sealed with thin strips of low-emitting aluminum foil tape. For carpet assemblies bonded with a tape system, the procedure was nearly identical except a 6 by 6-inch piece of tape was substituted for the adhesive. The tape specimen was cut from the material sample and the plastic film layer was removed from one side. The tape was hand pressed onto the plywood square. The film layer was removed from the top surface and the carpet specimen was hand pressed onto the tape. The back and edges of the plywood were sealed as described above.

For the hardback carpet and the carpet with an integral vinyl cushion, 6 by 6 -inch squares were cut from the material samples and then placed into a tightly fitting stainless steel tray that covered the back and cut edges of the specimens.

For resilient flooring materials, 6 by 6-inch squares were cut from the material samples and then attached to 6 by 6 -inch pieces of stainless steel sheet metal so that only the wear surface was exposed. Twelve-cm wide strips of aluminum foil tape were used to seal the edges. This tape created a border, which reduced the exposed surface of the flooring to 5.5 by 5.5 inches ( 14 by $14 \mathrm{~cm}$ ). This reduced area was used to calculate emission factors.

For ceiling panels, 6 by 6-inch squares were cut from the material samples and tested with all surfaces exposed. The surface area of one side of the specimen was used to calculate emission factors. This procedure was intended to simulate the installation of ceiling panels in a RC's suspended T-bar grid system. 


\section{Conditioning and testing of specimens}

The emissions of VOCs from the test specimens were determined following the guidance of ASTM D-5116-97 (ASTM, 1997). All specimens were initially conditioned prior to emission testing. This conditioning procedure has been used previously by others (e.g., Salthammer, 1997) and recently was shown to produce VOC emission factors generally in agreement within a factor of \pm 2 with emission factors measured in a manufactured house several months following its completion (Hodgson et al., 2001). The parameters used for conditioning and testing the specimens for emissions of VOCs are summarized in Table 1. Test specimens prepared as described above were immediately transferred to individual 19-L chambers and conditioned for a period of ten days. These chambers were supplied with charcoal filtered room air. At the end of the conditioning period, a test specimen was transferred to a 10.5-L chamber constructed of 316 stainless steel. This chamber was contained in an incubator to maintain the temperature at $23^{\circ} \mathrm{C}$. High-purity inlet nitrogen was split into two approximately equal streams. One of these was passed through a bubbler containing high-purity water. This was then mixed with the dry stream to produce a chamber humidity of near $50 \% \mathrm{RH}$. Samples for the analysis of VOCs and aldehydes were collected from the chamber exhaust at 96-h elapsed time.

\section{Sampling and analysis of VOCs and aldehydes}

The sampling and analytical methods and equipment for VOCs and low-molecular weight aldehydes, i.e., formaldehyde and acetaldehyde, are summarized in Table 2. For sampling, duplicate VOC sampling tubes and a single aldehyde sampler were attached to a manifold on the exhaust outlet of a small chamber. The VOC sampling rates were 100 $\mathrm{cm}^{3} \mathrm{~min}^{-1}$; the aldehyde sampling rate was $500 \mathrm{~cm}^{3} \mathrm{~min}^{-1}$. The remainder of the exit gas stream was freely vented. The VOC sample volumes were typically $2-3 \mathrm{~L}$; the aldehyde sample volume was $30 \mathrm{~L}$.

VOCs were qualitatively and quantitatively analyzed by thermal desorption-gas chromatography/mass spectrometry generally following U.S. EPA Methods TO-1 and TO-17. For qualitative analysis, compounds were identified by comparison of the unknown spectra and their corresponding chromatographic retention times with spectra 
and retention times for pure compounds analyzed under the same conditions. In some cases, tentative or probable identifications were obtained based on probable matches with spectra in electronic libraries. For quantitative analysis, multi-point internal standard calibrations were created using pure compounds and 1-bromo-4-fluorobenzene as the reference compound. The relative precision of the sampling and analysis method for VOCs has been determined to be about $\pm 10 \%$ for most compounds (Hodgson, 2000). The lower limit of quantitation for a $3-\mathrm{L}$ sample is about $0.5 \mu \mathrm{g} \mathrm{m}^{-3}$ for many compounds.

The aldehyde samples were extracted with acetonitrile, and the extracts were analyzed by high performance liquid chromatography with UV detection generally following U.S. EPA Method TO-11. Multi-point calibrations were prepared for formaldehyde and acetaldehyde using their respective hydrazone derivatives. Relative precision is better than $\pm 10 \%$. The lower limit of quantitation for a 30 -L sample is about $1 \mu \mathrm{g} \mathrm{m}^{-3}$.

\section{Data analysis}

VOC emission rates (mass per time) and emission factors (mass per area-time) were calculated for the chamber tests using the steady-state form of the mass-balance model for well-mixed chambers (ASTM, 1997). An emission factor $(E F)$ in $\mu \mathrm{g} \mathrm{m}^{-2} \mathrm{~h}^{-1}$ was calculated as:

$$
E F=\frac{Q\left(C-C_{O}\right)}{A}
$$

Where $Q$ is the chamber inlet gas flow rate $\left(\mathrm{m}^{3} \mathrm{~h}-1\right)$; $C$ is the gas-phase concentration of the compound in the chamber $\left(\mu \mathrm{g} \mathrm{m}^{-3}\right) ; C_{0}$ is the concentration of the compound in a blank chamber run $\left(\mu \mathrm{g} \mathrm{m}^{-3}\right)$; and $A$ is the exposed surface area of the material in the chamber $\left(\mathrm{m}^{2}\right)$.

The VOC emission factors for each material were multiplied by the projected surface area of the material exposed in an RC with exterior dimensions of 24 by $40-\mathrm{ft}$ ( 7.3 by 12.2-m) and an 8.5-ft (2.6-m) ceiling to produce estimates of classroom emission rates in $\mu \mathrm{g} \mathrm{h}^{-1}$. Then for each compound, the emission rates from the various materials in a 
classroom were summed. Indoor concentrations $\left(\mu \mathrm{g} \mathrm{m}^{-3}\right.$ ) were predicted by dividing these summed emission rates by the flow rates of outside air for different ventilation scenarios. These concentrations were converted to molar-volume units (parts-per-billion or ppb) assuming a temperature of $25^{\circ} \mathrm{C}$ and standard pressure.

\section{Results and Discussion}

\section{Material selection}

Table 3 shows the 17 materials selected and tested for emissions of VOCs. The RC manufacturer bonds the standard olefin fiber, broadloom carpet to the plywood subfloor with approximately 12 gallons ( $45 \mathrm{~L}$ ) of a solvent-free full-spread adhesive. Three alternate Nylon fiber broadloom carpets were tested. One of these was bonded to the plywood substrate with the same solvent-free adhesive. This carpet is the upgrade specified by School District A. The other two utilized a new generation adhesive mesh system. The adhesive mesh is first applied to cover the entire floor. Then, the top film is removed and the carpet is applied and rolled. Two alternate carpets with integral backings were tested. One of these had a chlorine-free hard backing. It can be applied to the floor using the same adhesive mesh system or with an adhesive. The other had an integral closed cell vinyl cushion backing and an integral adhesive system.

School District A specifies a commercial grade, sheet vinyl floor covering for the entry and area in front of the cabinetry. School District B specifies a vinyl composition floor tile for the entry and the area in front of the sink. A chlorine-free resilient floor tile was tested as an alternate.

The manufacturer finishes all four walls of their classrooms with vinyl covered fiberboard tackable wall panels. This is apparently standard industry practice, which allows teachers to easily display class and art work. We identified and tested four alternate tackable materials. One of these was the same fiberboard panel covered with Teflon-coated vinyl. This vinyl material is primarily intended for use on walls in need of frequent cleaning, such as walls in hospitals. Two of the alternates, both produced by a single manufacturer, were mineral fiber panels covered with vinyl and fabric materials. 
The final alternate was a fabric covered recycled paperboard panel claimed to be formaldehyde free.

The manufacturer finishes the grid ceilings of their classrooms using a fiberglass panel with a vinyl coating on its exposed surface. Two mineral fiber ceiling panels produced by a single manufacturer for institutional use, including schools, were selected as alternates. One was impregnated with an anti-microbial agent.

\section{Target compounds}

The chamber samples were first qualitatively analyzed to identify all of the VOCs emitted by each of the selected materials. Then the samples were quantitatively analyzed for chemicals of concern in California because of their toxicity and for odorous compounds. Three California programs have produced lists of toxic chemicals. These lists are identified in Table 4. The Toxic Air Contaminants (TACs) lists encompass almost all of the compounds in the Air Toxics Hot Spots Program and compounds covered under Proposition 65, which are found in indoor air with relatively high frequencies. The Air Toxics Hot Spots Program has established noncancer chronic Reference Exposure Levels (RELs) for a number of compounds. Approximately 21 of these compounds are relevant to studies of indoor air quality. The potential for a VOC to produce an odor effect was evaluated based on standardized human olfactory thresholds published by Devos et al. (1990). Although this is a comprehensive survey of the literature with data for over 500 compounds, odor thresholds have not been established for a number of VOCs emitted by materials and encountered in indoor air.

\section{VOC emissions from materials}

Table 5 presents the number of compounds by chemical class detected in the emissions from the floor covering materials. Table 6 presents the same information for the wall and ceiling materials. The VOC emissions from the vinyl composition tile (VCT) and the chlorine-free resilient floor tile (RFT) contained only a few compounds at detectable levels. The emissions from the sheet vinyl flooring (SVF) contained a relatively large number of aromatic hydrocarbons. Many of these were higher molecular weight alkyl-substituted benzenes. Among the carpets, the hardback carpet (HBC) and the vinyl cushion carpet (VCC) emitted the fewest compounds. The emissions from the 
four broadloom carpet assemblies (BLC1-BLC4) contained some compounds, principally aldehydes and terpene hydrocarbons, whose origin was likely the plywood substrate. The Teflon-coated vinyl covered wall panel (VWP2) emitted substantially fewer hydrocarbons than the standard vinyl covered wall panel (VWP1). The emissions from the fabric covered recycled paperboard wall panel (FWP2) contained a relatively large number of aldehydes and carboxylic acids. The carboxylic acids included butanoic and pentanoic acids, which have unpleasant odors and low part-per-billion odor thresholds (Devos et al., 1990). The fiberglass ceiling panel (FCP) and the two mineral fiber ceiling panels (MCP1 and MCP2) emitted relatively few compounds.

Emission factors for chemicals of concern and odorous compounds emitted by the carpet materials are presented in Table 7. The compounds in this and subsequent tables are listed by chemical class as given in Tables 5 and 6 and then in order of decreasing vapor pressure within class. Based on the typical lower limits of quantitation for the analyses, the exposed surface area of the specimens and the chamber flow rate, the lower limits for the emission factors are approximately $3 \mu \mathrm{g} \mathrm{m}^{-2} \mathrm{~h}^{-1}$ for formaldehyde and acetaldehyde and $1.5 \mu \mathrm{g} \mathrm{m}^{-2} \mathrm{~h}^{-1}$ for the other compounds. Values below these limits are not reported in the tables. In total, there were 11 compounds of concern with quantifiable emission factors. The two broadloom carpets bonded with the tape system (BLC3 and BLC4) had relatively high formaldehyde emission factors. This was likely due to emissions of formaldehyde from the plywood and/or possibly from the tape, which was not separately tested. BLC3 had Nylon 6 face fibers while the other carpets had Nylon 6,6 fibers. The emission factor for caprolactam, used to manufacture Nylon 6, was elevated for BLC3. All four broadloom carpet assemblies had measurable emission factors for hexanal and other aldehydes. These compounds likely originate from the plywood. Three of the broadloom carpets had emission factors for 4-phenylcyclohexene, the compound that produces the characteristic odor of carpets, in excess of $1.5 \mu \mathrm{g} \mathrm{m}^{-2} \mathrm{~h}^{-1}$.

Table 8 presents the emission factors for the resilient flooring materials. SVF had a relatively high phenol emission factor. These materials did not emit formaldehyde.

Three of the wall panels emitted measurable quantities of formaldehyde and all of the panels emitted acetaldehyde (Table 9). VWP1 and VWP2 were similar materials. The 
principal difference was that the vinyl fabric covering on VWP2 had a Teflon coating. The Teflon coating may have functioned as a partial diffusion barrier since the emission factors for vinyl acetate, the predominant compound emitted by these two materials, acetaldehyde, phenol, di(ethylene glycol)butyl ether, 1,2,4-trimethylbenzene and 1-methyl-2-pyrrolindinone decreased. Toluene emissions were associated with the Teflon-coated material. FWP2 had measurable emissions of five odorous aldehydes. The carboxylic acids emitted by this material were not quantified.

Table 10 presents the emission factors for the ceiling panels. FCP and MCP1 had similar formaldehyde emission factors even though they were fabricated with entirely different materials. None of the materials had measurable acetaldehyde emissions. MCP2 did not emit measurable amounts of any compounds of concern.

\section{Evaluation and selection of materials}

The alternate materials were evaluated for potential use in the classrooms based on a

number of criteria as summarized in Table 11. A primary objective of this study was to reduce the classroom concentrations of toxic chemicals of concern in California. The procedure for this evaluation was to estimate the airborne concentrations of these compounds in new RCs based on the measured emission factors, the exposed surface areas of the materials in the RCs, and the outside airflow rates at both ventilated and closed conditions. There are recommended RELs for some chemicals of concern. For these, the estimated concentrations were compared to the REL values. An identical procedure was used for odorous compounds, for which the estimated concentrations were compared to human odor thresholds (Devos et al., 199).

Materials used to finish the interiors of RCs must meet basic requirements with respect to appearance, durability, maintenance, sound properties and other factors. We qualitatively considered these factors in our initial selection of alternate materials. In addition, the incremental costs of purchasing the alternate materials were considered. This cost analysis was not rigorous and did not include maintenance costs or a life cycle analysis. It was further complicated by the fact that the manufacturer's current costs undoubtedly reflect substantial volume discounts. Thus, small volume purchases of alternate materials appear more expensive in comparison. 
Finally, the school districts and the manufacturer had the option to veto the selection of alternative materials. This was a significant factor in the final selection of the alternate carpets. School District A had a strong preference for a particular upgraded carpet based on prior experiences with other carpets and adhesive systems and was unwilling to consider another alternate. The selection of the alternate carpet was also restricted by the manufacturer's rejection of one of the choices, again based on a prior experience.

Broadloom carpets BLC3 and BLC4 bonded with a tape system were primarily rejected because they had relatively high formaldehyde emissions. Additionally, BLC3 had relatively high caprolactam emissions. The manufacturer rejected the vinyl cushion carpet. The resilient floor tile was not used due to its high initial cost relative to the standard materials. Also, the installed area of resilient flooring is relatively small, which diminishes the importance of this material category as a source. The fabric covered wall panels were rejected because of their high cost and the uncertain durability of the fabric in a school environment. Additionally, FWP2 emitted odorous carboxylic acids with a potential to result in occupant complaints. VWP3 was rejected due to its relatively high cost. Ceiling panels, FCP and MCP1 were rejected because they were sources of formaldehyde.

The materials selected for use in each of the four classrooms are listed in Table 12 by material category along with their projected surface areas. Classrooms RC 1c and RC 3c are to be finished with standard materials, except Classroom RC 1c is to receive an upgraded carpet as discussed above (the acronym suffix "c" indicates these classrooms are the experimental controls for the subsequent field study). Classrooms RC 2 and RC 4 are to be finished with alternate carpets (two different materials), wall panels and ceiling panels.

\section{Estimation of material impacts on indoor air quality}

The physical parameters for the classrooms are given in Table 13. Due to class size reduction policies, each classroom will likely serve twenty students and one teacher. To be in compliance with ASHRAE 62-1999, the minimum required outside airflow rate is $315 \mathrm{cfm}$ (i.e., $15 \mathrm{cfm}$ per occupant) or $535 \mathrm{~m}^{3} \mathrm{~h}^{-1}$. School District A specified a

minimum ventilation rate of $400 \mathrm{cfm}$ or $680 \mathrm{~m}^{3} \mathrm{~h}^{-1}$. Therefore, the VOC concentrations 
in the School District A classrooms were modeled at these two ventilation rate conditions. VOC concentrations in School District B classrooms were modeled at the minimum ASHRAE requirement. In addition, VOC concentrations in all classrooms were modeled for the overnight and weekend closed condition assuming an infiltration rate of $33 \mathrm{~m}^{3} \mathrm{~h}^{-1}$. This flow rate is equivalent to a ventilation rate of $0.15 \mathrm{~h}^{-1}$.

We first considered whether the use of alternate materials would likely reduce the number of detectable VOCs in indoor air. The numbers of detected compounds by chemical class emitted by all of the interior finish materials in each of the four classrooms are shown in Table 14. From this perspective, the use of alternate materials is expected to have only a minor impact in the School District A classrooms. The potential impact of alternate materials in School District B classrooms is more pronounced. In particular, there should be substantial reductions in the numbers of hydrocarbons due to the use of the alternates.

We next considered whether the alternate materials would likely reduce the concentrations of chemicals of concern. The predicted concentrations of these compounds are shown in Table 15 for the School District A classrooms and in Table 16 for the School District B classrooms. A comparison of the classrooms finished with alternate materials with their respective control classrooms indicates improvements are likely to be achieved.

Formaldehyde is of particular concern because it is a potent sensory irritant and is considered a probable human carcinogen. When the classrooms all are ventilated in compliance with ASHRAE 62-1999, the predicted formaldehyde concentrations are well below geometric mean concentrations measured in new manufactured and site-built houses of about $35 \mathrm{ppb}$ (Hodgson et al., 2000). Only the predicted formaldehyde concentration in RC 1c is elevated over the REL of $2 \mathrm{ppb}$, which is near typical urban outdoor air concentrations. The use of the mineral fiber ceiling panel in RC 2 and RC 4 removes the predominant formaldehyde source and results in predicted concentrations that are negligible at ventilated conditions.

Acetaldehyde has a REL that is near concentrations typically measured in buildings. The predicted acetaldehyde concentrations at ventilated conditions all are below 
geometric mean concentrations measured in new manufactured and site-built houses of 10 and $20 \mathrm{ppb}$, respectively (Hodgson et al., 2000). Only the predicted acetaldehyde concentration in RC 1c is elevated over the 5-ppb REL. Acetaldehyde concentrations in RC 2 and RC 4 are reduced primarily by use of Teflon-coated vinyl for the wall panels.

The predicted phenol concentrations at ventilated conditions are well below the 50-ppb REL and are within a factor of two of geometric mean concentrations measured in new manufactured and site-built houses of 2.6 and $1.4 \mathrm{ppb}$, respectively (Hodgson et al., 2000). Phenol concentrations in RC 2 and RC 4 are reduced primarily by use of Tefloncoated vinyl for the tackable wall panels.

Predicted concentrations of di(ethylene glycol) butyl ether, vinyl acetate, and 1-methyl-2-pyrrolidinone also are reduced in RC 2 and RC 4 primarily by the use of Teflon-coated vinyl for the tackable wall panels. This material, however, also results in the negative impact of relatively increased toluene concentrations in these classrooms. The predicted increase in toluene concentrations at ventilated conditions is less than $1 \mathrm{ppb}$, which is substantially below the 70-ppb REL for toluene.

In summary, the use of alternate materials with the classrooms operating at the minimum required ventilation rate results in predicted reductions in the concentrations of compounds of concern: $4 \mathrm{ppb}$ for formaldehyde, $2 \mathrm{ppb}$ for acetaldehyde, $3 \mathrm{ppb}$ for phenol, $1 \mathrm{ppb}$ for di(ethylene glycol) butyl ether, $27 \mathrm{ppb}$ for vinyl acetate, and $7 \mathrm{ppb}$ for 1-methyl-2-pyrrolidinone. There is an associated $<1 \mathrm{ppb}$ increase in toluene concentrations.

The predicted concentrations of odorous compounds are shown in Table 17 for the School District A classrooms and in Table 18 for the School District B classrooms. At ventilated conditions, the modeling results suggest no substantial odor problems in the classrooms attributable to the emissions of VOCs from the floor and the other interior finish materials should occur. The results also suggest odors will be noticeable when the classrooms are in the closed condition overnight and on weekends. Odor, however, is a highly complex biological response. Standard chemical analysis techniques generally are incapable of fully characterizing odors, particularly those due to complex mixtures. 


\section{Conclusions}

Our focus for this task was on the potential indoor concentrations of VOCs on three agencies' lists of compounds of concern in California. We additionally considered concentrations of odorous compounds, recognizing chemical analysis provides only an incomplete measure of the odor characteristics of materials. No attempt was made to estimate the combined potential health and odor impacts of mixtures of compounds. In addition, we did not consider the impacts of building related factors on the emissions of VOCs and their indoor concentrations. Such factors include the influence of ventilation rate on emission factors, the sorptive loss of less volatile compounds to other interior surfaces and their subsequent re-emission, and possible chemical transformations due to reactions with oxidants such as ozone.

The conclusions for this task are summarized in Table 19. In general, the carpet systems were not major sources of compounds of concern. However, the plywood subfloor under a broadloom carpet can be a source of formaldehyde and of higher molecular weight aldehdyes, which have very low odor thresholds. One clear benefit to be derived from the use of alternate materials is the elimination of the main formaldehyde source due to the use of ceiling panels with non-detectable emissions of formaldehyde. Switching to a Teflon-coated vinyl fabric for the tackable wall panels is predicted to reduce the classroom concentrations of acetaldehyde, phenol, di(ethylene glycol)butyl ether, vinyl acetate, 1,2,4-trimethylbenzene and 1-methyl-2-pyrrolidinone (the latter compound was added to the Proposition 65 list, June 2001). This effect is presumably due to the relatively low permeability of the added Teflon film. Finally, these data suggest there should be no substantial odor problems in either the standard or modified classrooms when they are ventilated in compliance with ASHRAE 62-1999.

The four RCs described in this report will be produced and delivered by the manufacturer in early summer 2001. At each of two elementary schools, a new RC with

alternate materials will be sited side-by-side with a new RC with standard materials. The standard RC will serve as the experimental control. The RCs will be instrumented to measure environmental factors including indoor and outdoor temperatures, humidities, noise, particle counts in six size bins, and $\mathrm{CO}_{2}$ concentrations. Additionally, they will be 
fitted with equipment for sampling VOCs and aldehydes. Concentrations of these contaminants in the unoccupied and unfurnished RCs will be measured on at least one occasion during the summer prior to the 2001-02 school year. Then, measurements will be conducted during occupied school hours for 8-10 weeks in the cooling and heating seasons. Measured concentrations, corrected for outdoor concentrations, will be compared to the concentrations predicted in this report to evaluate the efficacy of the VOC source reduction procedure. The added costs for substitution of the alternate materials will be quantitatively assessed based on the actual incremental construction costs for the RCs.

\section{Acknowledgements}

This study was sponsored by the California Energy Commission through the Public Interest Energy Research program as Element 6.2.2 of the Lawrence Berkeley National Laboratory High Performance Commercial Buildings Systems research contract number 400-99-012. The study was additionally supported by the U.S. Department of Energy under Lawrence Berkeley National Laboratory contract number DE-AC03-76SF00098. The authors thank the staff from American Modular Systems and several material manufacturers and/or distributors for collaborating with this study and for providing material specimens and information regarding the construction of modular classrooms. The authors also thank the school district participants for their cooperation and Marion Russell of LBNL for her assistance with the chemical analyses. Additional thanks go to Hal Levin for his review comments on this manuscript.

\section{References}

ASHRAE (1999) Ventilation for acceptable indoor air quality, Atlanta, GA, American Society of Heating, Refrigerating, and Air Conditioning Engineers (ASHRAE Standard 62-1999).

Devos, M., Patte, F., Rouault, J., Laffort, P. and Gmert, L.J. (1990) Standardized Human Olfactory Thresholds, New York, Oxford University Press. 
Hodgson, A.T., Rudd, A.F., Beal, D. and Chandra, S. (2000) Volatile organic compounds concentrations and emission rates in new manufactured and site-built houses, Indoor Air, 10, 178-192.

Hodgson, A.T., Beal, D. and McIlvaine, J.E.R. (2001) Sources of formaldehyde, other aldehydes and terpenes in a new manufactured house, Report No. LBNL-47627 Lawrence Berkeley National Laboratory, Berkeley, CA. Submitted to Indoor Air April 2001.

Kelly, T.J. (1996) Determination of formaldehyde and toluene diisocyanate emissions from indoor residential sources, Final Report Contract No. 93-315, California EPA, Air Resources Board, Sacramento, CA.

Kelly, T.J., Smith, D.L. and Satola, J. (1999) Emission rates of formaldehyde from materials and consumer products found in California Homes, Environmental Science and Technology, 33, 81-88.

Salthammer, T. (1997) Emission of volatile organic compounds from furniture coatings, Indoor Air, 7, 189-197.

Van Ert, M.D., Clayton, J.W., Crabb, C.L. and Walsh, D.W. (1987) Identification and characterization of 4-phenylcyclohexene - an emission product in new carpeting. U.S. EPA-OTS report, January. 
Table 1. Parameters for conditioning and testing material specimens for emissions of VOCs using small-volume chambers.

\begin{tabular}{lcc}
\hline Parameter & Units & Value \\
\hline Conditioning Period & & \\
Temperature & ${ }^{\circ} \mathrm{C}$ & $21 \pm 3$ \\
Relative humidity & $\% \mathrm{RH}$ & Ambient \\
Volume & $\mathrm{m}^{3}$ & 0.019 \\
Flow rate & $\mathrm{m}^{3} \mathrm{~h}^{-1}$ & 0.24 \\
Duration & $\mathrm{day}^{-1}$ & 10 \\
Test Period & & \\
Temperature & ${ }^{\circ} \mathrm{C}$ & $23 \pm 1$ \\
Relative Humidity & $\% \mathrm{RH}$ & $50 \pm 5$ \\
Volume & $\mathrm{m}^{3}$ & 0.0105 \\
Flow rate & $\mathrm{m}^{3} \mathrm{~h}^{-1}$ & $0.059 \pm 0.003$ \\
Ventilation rate & $\mathrm{h}^{-1}$ & 5.66 \\
Specimen area & $\mathrm{m}^{2}$ & $\sim 0.02$ \\
Loading ratio & $\mathrm{m}^{2} \mathrm{~m}^{-3}$ & $\sim 2$ \\
Area/Flow rate ratio & $\mathrm{m}^{2} / \mathrm{m}^{3} \mathrm{~h}^{-1}$ & $\sim 0.35$ \\
Sample collection elapsed time & $\mathrm{h}$ & 96 \\
\hline
\end{tabular}


Table 2. Summary of sampling and analytical methods and equipment for VOCs and low-molecular weight aldehydes.

Methods and Equipment

\section{VOC Sampling}

Tenax-TA sorbent tube; P/N CP16251, Varian Instr. Co. Modified by addition of Carbosieve S-III, 60/80 mesh backup section, P/N 10184, Supelco

VOC Analysis

Thermal desorption-gas chromatography/mass spectrometry (GC/MS); Model CP4020 TCT concentrator, Varian Instr. Co.; Models 6890 and 5973 MSD GC/MS system, Agilent

DB-1701 30-m, 0.25-mm, 1- $\mu$ m film column; P/N 122-0733 J\&W Scientific

\section{Formaldehyde \& Acetaldehyde Sampling}

XPoSure Aldehyde Sampler; P/N WAT047205, Waters Corp.

\section{Formaldehyde \& Acetaldehyde Analysis}

High performance Liquid Chromatography (HPLC); Model 1090M LC with DR-5 solvent delivery system \& diode array detector, Hewlett-Packard

Symmetry C 18 5- $\mu$ m 2.1 x 150-mm column; P/N WAT056975, Waters Corp. 
Table 3. Generic descriptions of standard (Std) and alternate (Alt) interior finish materials tested for emissions of VOCs.

\begin{tabular}{|c|c|c|}
\hline Material Description & Code* & Class \\
\hline \multicolumn{3}{|l|}{ Carpet } \\
\hline $\begin{array}{l}\text { Olefin fiber broadloom carpet bonded to plywood with } \\
\text { solvent-free full-spread adhesive }\end{array}$ & BLC1-s & Std \\
\hline $\begin{array}{l}\text { Nylon } 6,6 \text { fiber broadloom carpet bonded to plywood with } \\
\text { solvent-free full-spread adhesive }\end{array}$ & BLC2 & Alt \\
\hline $\begin{array}{l}\text { Nylon } 6 \text { fiber broadloom carpet bonded to plywood with } \\
\text { adhesive tape }\end{array}$ & BLC3 & Alt \\
\hline $\begin{array}{l}\text { Nylon } 6,6 \text { fiber broadloom carpet bonded to plywood with } \\
\text { adhesive tape }\end{array}$ & BLC4 & Alt \\
\hline Nylon 6,6 fiber olefin hardback carpet & $\mathrm{HBC}$ & Alt \\
\hline Nylon 6,6 fiber closed cell vinyl cushion carpet & VCC & Alt \\
\hline \multicolumn{3}{|l|}{ Resilient Flooring } \\
\hline Sheet vinyl flooring & SVF-S & Std \\
\hline Vinyl composition floor tile & VCT-s & Std \\
\hline Resilient floor tile, chlorine-free & RFT & Alt \\
\hline \multicolumn{3}{|l|}{ Tackable Wall Panel } \\
\hline Vinyl covered fiberboard wall panel & VWP1-s & Std \\
\hline Teflon-coated vinyl covered fiberboard wall panel & VWP2 & Alt \\
\hline Vinyl covered mineral fiber wall panel & VWP3 & Alt \\
\hline Fabric covered mineral fiber wall panel & FWP1 & Alt \\
\hline Fabric covered recycled paperboard wall panel & FWP2 & Alt \\
\hline \multicolumn{3}{|l|}{ Ceiling Panel } \\
\hline Fiberglass ceiling panel & FCP-s & Std \\
\hline Mineral fiber ceiling panel with anti-microbial agent & MCP1 & Alt \\
\hline Mineral fiber ceiling panel & MCP2 & Alt \\
\hline
\end{tabular}

*Suffix "s" indicates standard material 
Table 4. Lists of chemicals of concern in California.

\section{Latest}

Agency List

Revision

Air Toxics Hot Spots Program Risk Assessment Guidelines;

May 2000

Chemicals with Established Noncancer Chronic Reference Exposure

Levels (RELs); Calif. EPA, Office of Environmental Health Hazard

Assessment

Substances Identified as Toxic Air Contaminants (TACs, includes all

Mar. 2001

Hazardous Air Pollutants listed in the Federal Clean Air Act

Amendments of 1990); Calif. EPA, Air Resources Board

Safe Drinking Water and Toxic Enforcement Act of 1986 (Proposition

Feb. 2001 65); Chemicals Known to the State to Cause Cancer or Reproductive Toxicity; Calif. EPA, Office of Environmental Health Hazard Assessment 
Table 5. Number of detected compounds by chemical class emitted by four broadloom carpet/adhesive assemblies (BLC1-BLC4), a hardback carpet (HBC), a vinyl cushion carpet (VCC) and three resilient flooring materials (VCT, SVF and RFT).

\begin{tabular}{|c|c|c|c|c|c|c|c|c|c|}
\hline \multirow[b]{2}{*}{ Chemical Class } & \multicolumn{9}{|c|}{ Number of Compounds } \\
\hline & BLC1-s & BLC2 & BLC3 & BLC4 & $\mathrm{HBC}$ & $\mathrm{VCC}$ & VCT-s & SVF-S & RFT \\
\hline Aldehyde & 3 & 8 & 8 & 7 & 1 & 2 & & 1 & 1 \\
\hline Ketone & 1 & 2 & 1 & 1 & 1 & & & & \\
\hline Carboxylic acid & & 1 & 1 & 1 & 1 & 2 & & & \\
\hline Alcohol & 5 & 5 & 5 & 4 & 1 & 2 & 2 & 2 & \\
\hline Glycol ether & & 1 & 3 & 3 & & & 1 & & \\
\hline Acetate and ester & 2 & 1 & 2 & 3 & & 1 & & 2 & 1 \\
\hline Chlorinated compound & 1 & 1 & & & & & & & \\
\hline Aromatic $\mathrm{HC}^{\mathrm{a}}$ & 4 & 7 & 1 & 1 & 6 & & & 19 & 1 \\
\hline Terpene HC & 10 & 8 & 1 & 1 & & & & & \\
\hline Alkene HC & & & & & & 1 & & & \\
\hline Cyclic HC & 5 & 3 & & & & & & & \\
\hline Alkane HC & 4 & 5 & 2 & 2 & & & & 4 & 1 \\
\hline Nitrogen compound & 1 & & 2 & 1 & 1 & 1 & & & \\
\hline Unidentified compound & & & & 3 & & 2 & 1 & 10 & \\
\hline Total Number & 36 & 42 & 26 & 27 & 11 & 11 & 4 & 42 & 4 \\
\hline
\end{tabular}

${ }^{\mathrm{a}} \mathrm{HC}=$ Hydrocarbon

${ }^{\mathbf{b}}$ Material codes are defined in Table 3 
Table 6. Number of detected compounds by chemical class emitted by three vinyl covered (VWP1-VWP3) and two fabric covered (FWP1 and FWP2) wall panels, a fiberglass ceiling panel (FCP) and two mineral fiber ceiling panels (MCP1 and MCP2).

\begin{tabular}{|c|c|c|c|c|c|c|c|c|}
\hline Chemical Class & VWP1-s ${ }^{\mathbf{b}}$ & VWP2 & VWP3 & $\begin{array}{c}\text { Number o } \\
\text { FWP1 }\end{array}$ & $\begin{array}{l}\text { mpound } \\
\text { FWP2 }\end{array}$ & FCP-s & MCP1 & MCP2 \\
\hline Aldehyde & 2 & 2 & 4 & 5 & 9 & 1 & 2 & 1 \\
\hline Ketone & & & & & 1 & & & \\
\hline Carboxylic acid & 1 & & 2 & 1 & 5 & & & \\
\hline Alcohol & 3 & 1 & 1 & 1 & & 1 & & \\
\hline Glycol ether & 1 & & 1 & 2 & 1 & & 2 & \\
\hline Acetate and ester & 1 & 3 & & & 1 & & 1 & 1 \\
\hline Chlorinated compound & & & & 1 & & & & \\
\hline Aromatic $\mathrm{HC}^{\mathbf{a}}$ & 9 & 1 & 12 & 4 & & & & \\
\hline Terpene HC & & & & & & & 1 & \\
\hline Cyclic HC & 3 & & 3 & & & & & \\
\hline Alkane HC & 8 & 2 & 2 & & 1 & & & \\
\hline Nitrogen compound & 1 & & & & & & 1 & \\
\hline Silicone compound & 1 & & & & & & & \\
\hline Unidentified compound & & & & & & 1 & & 1 \\
\hline Total Number & 30 & 9 & 25 & 14 & 18 & 3 & 7 & 3 \\
\hline
\end{tabular}

${ }^{\mathrm{a}} \mathrm{HC}=$ Hydrocarbon

${ }^{\mathbf{b}}$ Material codes are defined in Table 3 
Table 7. Emission factors for chemicals of concern and quantified odorous VOCs emitted by four broadloom carpet/adhesive assemblies (BLC1-BLC4), a hardback carpet (HBC) and a vinyl cushion carpet (VCC).

\begin{tabular}{|c|c|c|c|c|c|c|c|}
\hline \multirow[b]{2}{*}{ Compound } & \multirow{2}{*}{$\begin{array}{l}\text { Toxic } \\
\text { Cat. }^{\mathbf{c}}\end{array}$} & \multicolumn{6}{|c|}{ Emission Factor, $\mu \mathrm{g} \mathrm{m}^{-2} \mathrm{~h}^{-1}$} \\
\hline & & BLC1-s ${ }^{\mathbf{d}}$ & BLC2 & BLC3 & BLC4 & $\mathrm{HBC}$ & VCC \\
\hline \multicolumn{8}{|l|}{ Toxic Compounds } \\
\hline Formaldehyde & II a, P & & & 29.4 & 38.2 & 4.0 & \\
\hline Acetaldehyde & II a, P & & 23.6 & 13.0 & 22.8 & & 6.3 \\
\hline 2-Butanone & II a & & 3.4 & & & & \\
\hline Isophorone & II a & & & & & 1.7 & \\
\hline 1-Butanol & IV b & & & 11.9 & 9.4 & & \\
\hline DEGBE $^{\mathbf{a}}$ & II a & & 6.0 & & & & \\
\hline Tetrachloroethene & I, P & & 1.7 & & & & \\
\hline Styrene & II a & 1.7 & & & & & \\
\hline Naphthalene & II a & & 3.4 & & & & \\
\hline $\begin{array}{l}\text { 1-Methyl-2- } \\
\text { pyrrolidinone }\end{array}$ & $\mathrm{P}$ & 4.3 & & & & & \\
\hline Caprolactam & V & & & 126 & 7.7 & 8.5 & \\
\hline \multicolumn{8}{|c|}{ Odorous Compounds } \\
\hline Hexanal & -- & 21.3 & 41.0 & 46.5 & 41.7 & & \\
\hline Octanal & -- & & 1.7 & & & & \\
\hline 2-Octenal & -- & & 1.7 & 5.1 & 3.4 & & \\
\hline Nonanal & -- & & & 6.6 & 2.9 & & \\
\hline 2-Nonenal & -- & & 4.3 & & & & \\
\hline Decanal & -- & & 1.7 & 2.7 & 2.4 & & 1.8 \\
\hline a-Terpineol & -- & 9.4 & 2.6 & & & & \\
\hline 4- $\mathrm{PCH}^{\mathbf{b}}$ & -- & 3.4 & & 2.6 & 1.7 & & \\
\hline
\end{tabular}

${ }^{\mathrm{a} D i}$ (ethylene glycol)butyl ether or 2-(2-butoxyethoxy)ethanol

b-Phenylcyclohexene

${ }^{\mathrm{c}}$ Toxic Air Contaminant category (I, II a, IV b, V); reproductive toxicant on Proposition 65 (P) list

${ }^{\mathrm{d}}$ Material codes are defined in Table 3 
Table 8. Emission factors for chemicals of concern emitted by three resilient flooring materials (VCT, SVF and RFT). No odorous VOCs were detected at quantifiable levels.

\begin{tabular}{lcccc}
\hline Compound & Toxic & \multicolumn{3}{c}{ Emission Factor, $\mu \mathrm{g} \mathrm{m}^{-2} \mathrm{~h}^{-1}$} \\
& Cat. $^{\mathbf{c}}$ & VCT-s $^{\mathbf{d}}$ & SVF-s & RFT \\
\hline Acetaldehyde & II a, P & & 12.8 & 4.3 \\
Phenol & II a & & 240 & \\
DEGBE $^{\mathbf{a}}$ & II a & 5.3 & & \\
Toluene $_{1,2,4-\mathrm{TMB}^{\mathbf{b}}}$ & II a, P & & & 5.8 \\
\hline
\end{tabular}

${ }^{\text {a }}$ Di(ethylene glycol)butyl ether or 2-(2-butoxyethoxy)ethanol

b 1,2,4-Trimethylbenzene

${ }^{\mathrm{c}}$ Toxic Air Contaminant category (II a, IV b); reproductive toxicant on Proposition $65(\mathrm{P})$ list

${ }^{\mathrm{d}}$ Material codes are defined in Table 3 
Table 9. Emission factors for chemicals of concern and quantified odorous VOCs emitted by three vinyl covered (VWP1-VWP3) and two fabric covered (FWP1 and FWP2) wall panels.

\begin{tabular}{|c|c|c|c|c|c|c|}
\hline \multirow[b]{2}{*}{ Compound } & \multirow{2}{*}{$\begin{array}{l}\text { Toxic } \\
\text { Cat. }^{\mathbf{c}}\end{array}$} & \multicolumn{5}{|c|}{ Emission Factor, $\mu \mathrm{g} \mathrm{m}^{-2} \mathrm{~h}^{-1}$} \\
\hline & & VWP1-s & VWP2 & VWP3 & FWP1 & FWP2 \\
\hline \multicolumn{7}{|l|}{ Toxic Compounds } \\
\hline Formaldehyde & II a, P & & & 11.7 & 9.1 & 17.0 \\
\hline Acetaldehyde & II a, P & 46.4 & 22.8 & 4.4 & 5.7 & 50.8 \\
\hline Acetophenone & II a & & & & & 3.0 \\
\hline Phenol & II a & 52.6 & 6.1 & 18.3 & & \\
\hline $\mathrm{DEGBE}^{\mathrm{a}}$ & II a & 50.1 & & & & \\
\hline Vinyl acetate & II a & 842 & 293 & & & \\
\hline Dichloromethane & II a, P & & & & 14.2 & \\
\hline Toluene & II a, P & & 20.3 & & 3.0 & \\
\hline m-,p-Xylene & II a & & & 2.0 & & \\
\hline o-Xylene & II a & & & 2.0 & & \\
\hline $1,2,4-\mathrm{TMB}^{\mathbf{b}}$ & IV b & 10.0 & & 10.2 & & \\
\hline Naphthalene & II a & & & 3.0 & & \\
\hline $\begin{array}{l}\text { 1-Methyl-2- } \\
\text { pyrrolidinone }\end{array}$ & $\mathrm{P}$ & 158 & & & & \\
\hline \multicolumn{7}{|c|}{ Odorous Compounds } \\
\hline Hexanal & -- & & & & & 8.8 \\
\hline Heptanal & -- & & & & & 2.7 \\
\hline Octanal & -- & & & & & 2.9 \\
\hline Nonanal & -- & & & 4.9 & 2.3 & 3.5 \\
\hline 2-Nonenal & -- & & & & & 3.0 \\
\hline Decanal & -- & 7.5 & 2.0 & 5.1 & 3.8 & \\
\hline
\end{tabular}

${ }^{a}$ Di(ethylene glycol)butyl ether or 2-(2-butoxyethoxy)ethanol

b 1,2,4-Trimethylbenzene

${ }^{\mathbf{c}}$ Toxic Air Contaminant category (II a, IV b); reproductive toxicant on Proposition 65 (P) list

dMaterial codes are defined in Table 3 
Table 10. Emission factors for chemicals of concern and quantified odorous VOCs emitted by a fiberglass ceiling panel (FCP) and two mineral fiber ceiling panels (MCP1 and MCP2).

\begin{tabular}{|c|c|c|c|c|}
\hline \multirow[b]{2}{*}{ Compound } & \multirow{2}{*}{$\begin{array}{l}\text { Toxic } \\
\text { Cat. }^{\text {b }}\end{array}$} & \multicolumn{3}{|c|}{ Emission Factor, $\mu \mathrm{g} \mathrm{m}^{-2} \mathrm{~h}^{-1}$} \\
\hline & & $\mathrm{FCP}-\mathrm{s}$ & MCP1 & MCP2 \\
\hline \multicolumn{5}{|c|}{ Toxic Compounds } \\
\hline Formaldehyde & II a, P & 32.0 & 26.7 & \\
\hline Phenol & II a & 18.1 & & \\
\hline DEGBE $^{\mathrm{a}}$ & II a & & 61.4 & \\
\hline \multicolumn{5}{|c|}{ Odorous Compounds } \\
\hline Nonanal & -- & & 2.1 & 2.6 \\
\hline
\end{tabular}

${ }^{a}$ Di(ethylene glycol)butyl ether or 2-(2-butoxyethoxy)ethanol

${ }^{\mathbf{b}}$ Toxic Air Contaminant category (II a, IV b); reproductive toxicant on

Proposition $65(\mathrm{P})$ list

${ }^{\mathbf{c}}$ Material codes are defined in Table 3 
Table 11. Summary of procedures for evaluating and selecting materials.

\begin{tabular}{ll}
\hline Parameter & Evaluation Procedure \\
\hline $\begin{array}{l}\text { Chemicals of concern and } \\
\text { odorous compounds }\end{array}$ & $\begin{array}{c}\text { Estimate concentrations for ventilated and closed } \\
\text { conditions using emission factors and classroom } \\
\text { parameters }\end{array}$ \\
Compounds with RELs & Compare estimated concentrations with guideline values \\
Odorous compounds & Compare estimated concentrations with odor thresholds \\
Material performance & $\begin{array}{c}\text { Consider appearance, durability, maintenance } \\
\text { requirements, sound properties, etc. }\end{array}$ \\
Cost & $\begin{array}{c}\text { Compare material and installed costs of standard and } \\
\text { alternate materials }\end{array}$ \\
Acceptability & School districts and manufacturer can reject \\
& recommended alternate materials
\end{tabular}


Table 12. Projected surface areas of materials selected to finish the interiors of the four relocatable classrooms (RCs).

Surface Area, $\mathrm{m}^{2}$

Sch. Dist. A Sch. Dist. B

Material Description

Code $\mathrm{RC} 1 \mathrm{c} * \quad \mathrm{RC} 2 \mathrm{RC} 3 \mathrm{c}^{*} \quad \mathrm{RC} 4$

\section{Floor}

Olefin fiber broadloom carpet bonded to

BLC1-S

81.5

plywood with solvent-free full-spread

adhesive

Nylon 6,6 fiber, olefin hardback carpet

bonded to plywood with adhesive tape

Nylon 6,6 fiber broadloom carpet

bonded to plywood with solvent-free

full-spread adhesive

Vinyl composition floor tiles

VCT-s

$3.3 \quad 3.3$

Sheet vinyl flooring

$\begin{array}{lll}\text { SVF-s } & 12.8 \quad 12.8\end{array}$

Walls

Vinyl covered fiberboard wall panels

VWP1 92.0

92.0

Teflon-coated vinyl covered fiberboard

VWP2

92.0

92.0

wall panels

\section{Ceiling}

Fiberglass ceiling panels

FCP-s $\quad 84.8$

84.8

Mineral fiber ceiling panels

MCP2

84.8

84.8

*Suffix "c" indicates classrooms are the experimental controls for subsequent field study 
Table 13. Physical parameters for relocatable classrooms.

\begin{tabular}{lcc}
\hline Parameter & Units & Value \\
\hline Floor Area & $\mathrm{m}^{2}$ & 84.8 \\
Volume & $\mathrm{m}^{3}$ & 220 \\
Ventilation Rate* & & \\
$\quad @ 680 \mathrm{~m}^{3} \mathrm{~h}^{-1}(400 \mathrm{cfm})$ & $\mathrm{h}^{-1}$ & 3.1 \\
$@ 535 \mathrm{~m}^{3} \mathrm{~h}^{-1}(315 \mathrm{cfm})$ & $\mathrm{h}^{-1}$ & 2.4 \\
$@ 33 \mathrm{~m}^{3} \mathrm{~h}^{-1}(19.4 \mathrm{cfm})$ & $\mathrm{h}^{-1}$ & 0.15
\end{tabular}

\section{Loading Ratio}

$\begin{array}{llc}\text { Carpet } & \mathrm{m}^{2} \mathrm{~m}^{-3} & 0.33-0.37 \\ \text { Resilient floor } & \mathrm{m}^{2} \mathrm{~m}^{-3} & 0.02-0.06 \\ \text { Wall } & \mathrm{m}^{2} \mathrm{~m}^{-3} & 0.42 \\ \text { Ceiling } & \mathrm{m}^{2} \mathrm{~m}^{-3} & 0.39\end{array}$

*Modeled rates correspond to enhanced outside airflow rate specified by School District A, minimum outside airflow rate for 21 occupants in compliance with ASHRAE 62-1999, and estimated infiltration rate for closed condition, respectively 
Table 14. Number of detected compounds by chemical class emitted by the interior finish materials selected for the four relocatable classrooms (RCs).

\begin{tabular}{lcccc}
\hline & \multicolumn{4}{c}{ Number of Compounds } \\
Chemical Class & Sch. Dist. A & \multicolumn{2}{c}{ Sch. Dist. B } \\
\hline Aldehyde & 10 & 10 & 6 & 5 \\
Ketone & 3 & 3 & 1 & 2 \\
Carboxylic acid & 2 & 1 & 1 & 2 \\
Alcohol & 8 & 7 & 8 & 5 \\
Glycol ether & 1 & 1 & 1 & 1 \\
Acetate and ester & 4 & 6 & 3 & 4 \\
Chlorinated HC* & 1 & 1 & & 1 \\
Chlorinated alcohol & & & 1 & \\
Aromatic HC & 32 & 28 & 14 & 9 \\
Terpene HC & 8 & 8 & 10 & \\
Alkene HC & 4 & 4 & & \\
Cyclic HC & 6 & 3 & 8 & \\
Alkane HC & 15 & 9 & 11 & 3 \\
Nitrogen compound & 1 & & 1 & 1 \\
Silicone compound & 1 & & 66 & 34 \\
\hline Total Number & 96 & 81 & & \\
\hline
\end{tabular}

$* \mathrm{HC}=$ Hydrocarbon 
Table 15. Predicted concentrations in RC 1c and RC 2, School District A, for chemicals of concern. The modeled outside airflow rates of 680,535 and $33 \mathrm{~m}^{3} \mathrm{~h}^{-1}$ correspond to enhanced ventilation, minimum ventilation and estimated infiltration, respectively. The identified sources of the VOCs also are indicated.

\begin{tabular}{|c|c|c|c|c|c|c|c|c|c|c|}
\hline \multirow[b]{2}{*}{ Compound } & \multirow[b]{2}{*}{$\begin{array}{l}\text { Toxic } \\
\text { Cat. }^{\mathbf{c}}\end{array}$} & \multirow[b]{2}{*}{$\begin{array}{c}\mathrm{REL}^{\mathbf{d}} \\
\mathrm{ppb}\end{array}$} & \multicolumn{6}{|c|}{ Predicted Concentration, ppb } & \multirow[b]{2}{*}{$\begin{array}{c}\text { RC 1c } \\
\text { Identified } \\
\text { Sources }\end{array}$} & \multirow[b]{2}{*}{$\begin{array}{c}\text { RC } 2 \\
\text { Identified } \\
\text { Sources }\end{array}$} \\
\hline & & & $\begin{array}{l}\text { @ } 680 \\
\mathrm{~m}^{3} \mathrm{~h}^{-1}\end{array}$ & $\begin{array}{l}\mathrm{RC} 1 \mathrm{c} \\
@ 535 \\
\mathrm{~m}^{3} \mathrm{~h}^{-1}\end{array}$ & $\begin{array}{l}@ 33 \\
\mathrm{~m}^{3} \mathrm{~h}^{-1}\end{array}$ & $\begin{array}{l}@ 680 \\
\mathrm{~m}^{3} \mathrm{~h}^{-1}\end{array}$ & $\begin{array}{l}\text { RC } 2 \\
@ 535 \\
\mathrm{~m}^{3} \mathrm{~h}^{-1}\end{array}$ & $\begin{array}{l}@ 33 \\
\mathrm{~m}^{3} \mathrm{~h}^{-1}\end{array}$ & & \\
\hline Formaldehyde & II a, P & 2 & 3.3 & 4.1 & 67.1 & -- & -- & -- & $\mathrm{CP}$ & \\
\hline Acetaldehyde & II a, P & 5 & 5.0 & 6.4 & 103 & 3.2 & 4.1 & 66.7 & $\mathrm{C}, \mathrm{SVF}, \mathrm{WP}$ & $\mathrm{C}, \mathrm{SVF}, \mathrm{WP}$ \\
\hline 2-Butanone & II a & & 0.1 & 0.2 & 2.5 & 0.1 & 0.2 & 2.5 & $\mathrm{C}$ & $\mathrm{C}$ \\
\hline Phenol & II a & 50 & 3.6 & 4.6 & 74.5 & 1.4 & 1.8 & 28.6 & $\mathrm{SVF}, \mathrm{WP}, \mathrm{CP}$ & SVF, WP \\
\hline $\operatorname{DEGBE}^{\mathbf{a}}$ & II a & & 1.1 & 1.4 & 23.1 & 0.1 & 0.1 & 2.0 & $\mathrm{C}, \mathrm{WP}$ & $\mathrm{C}$ \\
\hline Vinyl acetate & II a & & 32.4 & 41.2 & 668 & 11.3 & 14.4 & 233 & WP & WP \\
\hline Tetrachloroethene & $\mathrm{I}, \mathrm{P}$ & & $<0.1$ & $<0.1$ & 0.5 & $<0.1$ & $<0.1$ & 0.5 & $\mathrm{C}$ & $\mathrm{C}$ \\
\hline Toluene & II a, P & 70 & -- & -- & -- & 0.7 & 0.9 & 15.1 & & WP \\
\hline $1,2,4-\mathrm{TMB}^{\mathbf{b}}$ & IV b & & 0.4 & 0.5 & 7.8 & 0.1 & 0.1 & 2.1 & SVF, WP & SVF \\
\hline Naphthalene & II a & 2 & 0.1 & 0.1 & 1.4 & 0.1 & 0.1 & 1.4 & $\mathrm{C}$ & $\mathrm{C}$ \\
\hline $\begin{array}{l}\text { 1-Methyl-2- } \\
\text { pyrrolidinone }\end{array}$ & $\mathrm{P}$ & & 5.3 & 6.7 & 109 & -- & -- & -- & WP & \\
\hline
\end{tabular}

${ }^{\text {a }} \mathrm{Di}($ ethylene glycol)butyl ether or 2-(2-butoxyethoxy)ethanol

${ }^{b} 1,2,4$-Trimethylbenzene

${ }^{\mathbf{c}}$ Toxic Air Contaminant category (I, II a, IV b); reproductive toxicant on Proposition 65 (P) list

${ }^{\mathbf{d}}$ Noncancer chronic Reference Exposure Level established by the Office of Environmental Health Hazard Assessment (OEHHA)

${ }^{\mathrm{e}} \mathrm{C}=$ Carpet, $\mathrm{CP}=$ ceiling panel, $\mathrm{SVF}=$ sheet vinyl flooring, $\mathrm{WP}=$ wall panel 
Table 16. Predicted concentrations in RC 3c and RC 4, School District B, for chemicals of concern. The modeled outside airflow rates of 535 and $33 \mathrm{~m}^{3} \mathrm{~h}^{-1}$ correspond to minimum ventilation and estimated infiltration, respectively. The identified sources of the VOCs also are indicated.

\begin{tabular}{|c|c|c|c|c|c|c|c|c|}
\hline \multirow[b]{3}{*}{ Compound } & \multirow[b]{3}{*}{$\begin{array}{l}\text { Toxic } \\
\text { Cat. }^{\mathbf{c}}\end{array}$} & \multirow[b]{3}{*}{$\begin{array}{c}\mathrm{REL}^{\mathbf{d}} \\
\mathrm{ppb}\end{array}$} & \multicolumn{4}{|c|}{ Predicted Concentration, ppb } & \multirow{3}{*}{$\begin{array}{c}\text { RC 3c } \\
\text { Identified } \\
\text { Sources }\end{array}$} & \multirow{3}{*}{$\begin{array}{c}\text { RC } 4 \\
\text { Identified } \\
\text { Sources }\end{array}$} \\
\hline & & & \multicolumn{2}{|c|}{$\mathrm{RC} 3 \mathrm{c}$} & \multicolumn{2}{|c|}{$\mathrm{RC} 4$} & & \\
\hline & & & $\begin{array}{l}\text { @ } 535 \\
\mathrm{~m}^{3} \mathrm{~h}^{-1}\end{array}$ & $\begin{array}{l}\text { @ } 33 \\
\mathrm{~m}^{3} \mathrm{~h}^{-1}\end{array}$ & $\begin{array}{l}\text { @ } 535 \\
\mathrm{~m}^{3} \mathrm{~h}^{-1} \\
\end{array}$ & $\begin{array}{l}\text { @ } 33 \\
\mathrm{~m}^{3} \mathrm{~h}^{-1}\end{array}$ & & \\
\hline Formaldehyde & II a, P & 2 & 4.1 & 67.1 & $<1$ & 8.1 & $\mathrm{CP}$ & $\mathrm{C}$ \\
\hline Acetaldehyde & II a, P & 5 & 4.4 & 71.9 & 2.2 & 35.4 & WP & WP \\
\hline Isophorone & II a & & -- & -- & $<0.1$ & 0.7 & & $\mathrm{C}$ \\
\hline Phenol & II a & 50 & 3.1 & 50.3 & 0.3 & 4.4 & $\mathrm{WP}, \mathrm{CP}$ & WP \\
\hline $\mathrm{DEGBE}^{\mathbf{a}}$ & II a & & 1.3 & 21.2 & $<0.1$ & 0.1 & VCT, WP & VCT \\
\hline Vinyl acetate & II a & & 41.2 & 668 & 14.4 & 233 & WP & WP \\
\hline Toluene & II a, P & 70 & -- & -- & 0.9 & 15.1 & & WP \\
\hline Styrene & II a & 200 & 0.1 & 1.0 & -- & -- & $\mathrm{C}$ & \\
\hline $1,2,4-\mathrm{TMB}^{\mathbf{b}}$ & IV b & & 0.4 & 5.7 & -- & -- & WP & \\
\hline 1-Methyl-2-pyrrolidinone & $\mathrm{P}$ & & 6.9 & 111 & -- & -- & $\mathrm{C}, \mathrm{WP}$ & \\
\hline Caprolactam & $\mathrm{V}$ & & -- & -- & 0.3 & 4.6 & & $\mathrm{C}$ \\
\hline
\end{tabular}

${ }^{a}$ Di(ethylene glycol)butyl ether or 2-(2-butoxyethoxy)ethanol

b 1,2,4-Trimethylbenzene

${ }^{\mathrm{c}}$ Toxic Air Contaminant category (II a, IV b, V); reproductive toxicant on Proposition 65 (P) list

${ }^{\mathbf{d}}$ Noncancer chronic Reference Exposure Level established by the Office of Environmental Health Hazard Assessment (OEHHA)

${ }^{\mathrm{e}} \mathrm{C}=$ Carpet, $\mathrm{CP}=$ ceiling panel, $\mathrm{VCT}=$ vinyl composition tile, $\mathrm{WP}=$ wall panel 
Table 17. Predicted concentrations in RC 1c and RC 2, School District A, for VOCs with low odor thresholds or odor thresholds similar in magnitude to the predicted concentrations. The modeled outside airflow rates of 680,535 and $33 \mathrm{~m}^{3} \mathrm{~h}^{-1}$ correspond to enhanced ventilation, minimum ventilation and estimated infiltration, respectively.

\begin{tabular}{|c|c|c|c|c|c|c|c|}
\hline \multirow[b]{2}{*}{ Compound } & \multirow[b]{2}{*}{$\begin{array}{l}\text { OT* } \\
\text { ppb }\end{array}$} & \multicolumn{6}{|c|}{ Predicted Concentration, ppb } \\
\hline & & $\begin{array}{l}\text { @ } 680 \\
\mathrm{~m}^{3} \mathrm{~h}^{-1}\end{array}$ & $\begin{array}{l}\mathrm{RC} \mathrm{1c} \\
@ 535 \\
\mathrm{~m}^{3} \mathrm{~h}^{-1}\end{array}$ & $\begin{array}{c}\text { @ } 33 \\
\mathrm{~m}^{3} \mathrm{~h}^{-1} \\
\end{array}$ & $\begin{array}{l}\text { @ } 680 \\
\mathrm{~m}^{3} \mathrm{~h}^{-1}\end{array}$ & $\begin{array}{l}\mathrm{RC} 2 \\
\text { @ } 535 \\
\mathrm{~m}^{3} \mathrm{~h}^{-1}\end{array}$ & $\begin{array}{c}@ 33 \\
\mathrm{~m}^{3} \mathrm{~h}^{-1}\end{array}$ \\
\hline Hexanal & 13.8 & 1.1 & 1.3 & 21.9 & 1.1 & 1.3 & 21.9 \\
\hline Octanal & 1.3 & $<0.1$ & $<0.1$ & 0.7 & $<0.1$ & $<0.1$ & 0.7 \\
\hline 2-Octenal & 2.0 & $<0.1$ & $<0.1$ & 0.7 & $<0.1$ & $<0.1$ & 0.7 \\
\hline Nonanal & 2.2 & -- & -- & -- & 0.1 & 0.1 & 1.1 \\
\hline 2-Nonenal & 0.15 & 0.1 & 0.1 & 1.6 & 0.1 & 0.1 & 1.6 \\
\hline Decanal & 0.9 & 0.2 & 0.2 & 3.9 & 0.1 & 0.1 & 1.5 \\
\hline Phenol & 110 & 3.6 & 4.6 & 74.5 & 1.4 & 1.8 & 28.6 \\
\hline$\alpha$-Terpineol & 37 & $<0.1$ & 0.1 & 0.9 & $<0.1$ & 0.1 & 0.9 \\
\hline Vinyl acetate & 600 & 32.4 & 41.2 & 668 & 11.3 & 14.4 & 233 \\
\hline Naphthalene & 14.8 & 0.1 & 0.1 & 1.4 & 0.1 & 0.1 & 1.4 \\
\hline
\end{tabular}

*Odor thresholds are from Devos et al., 1990 
Table 18. Predicted concentrations in RC 3c and RC 4, School District B, for VOCs with low odor thresholds or odor thresholds similar in magnitude to the predicted concentrations. The modeled outside airflow rates of 535 and $33 \mathrm{~m}^{3} \mathrm{~h}^{-1}$ correspond to minimum ventilation and estimated infiltration, respectively.

\begin{tabular}{|c|c|c|c|c|c|}
\hline \multirow[b]{3}{*}{ Compound } & \multirow[b]{3}{*}{$\begin{array}{l}\mathrm{OT}^{\mathbf{b}} \\
\mathrm{ppb}\end{array}$} & \multicolumn{4}{|c|}{ Predicted Concentration, ppb } \\
\hline & & \multicolumn{2}{|c|}{$\mathrm{RC} \mathrm{3c}$} & \multicolumn{2}{|c|}{$\mathrm{RC} 4$} \\
\hline & & $\begin{array}{c}\text { @ } 535 \\
\mathrm{~m}^{3} \mathrm{~h}^{-1}\end{array}$ & $\begin{array}{c}\text { @ } 33 \\
\mathrm{~m}^{3} \mathrm{~h}^{-1}\end{array}$ & $\begin{array}{l}\text { @ } 535 \\
\mathrm{~m}^{3} \mathrm{~h}^{-1}\end{array}$ & $\begin{array}{l}\text { @ } 33 \\
\mathrm{~m}^{3} \mathrm{~h}^{-1}\end{array}$ \\
\hline Hexanal & 13.8 & 0.8 & 12.8 & -- & -- \\
\hline Nonanal & 2.2 & -- & -- & 0.1 & 1.1 \\
\hline Decanal & 0.9 & 0.2 & 3.3 & 0.1 & 0.9 \\
\hline Phenol & 110 & 3.1 & 50.3 & 0.3 & 4.4 \\
\hline$\alpha$-Terpineol & 37 & 0.2 & 3.7 & -- & -- \\
\hline Vinyl acetate & 600 & 41.2 & 668 & 14.4 & 233 \\
\hline $4-\mathrm{PCH}^{\mathrm{a}}$ & $0.5^{\mathrm{c}}$ & 0.1 & 1.3 & -- & -- \\
\hline
\end{tabular}

a4-Phenylcyclohexene

${ }^{\text {b }}$ Odor thresholds are from Devos et al., 1990 with the exception of value for 4-PCH ${ }^{\mathrm{c}}$ Value is from Van Ert et al., 1987 
Table 19. Summary of conclusions from study of VOC emissions from standard and alternate materials.

\section{Conclusions}

Tested carpet systems were not major sources of compounds of concern.

Glue-down carpet systems apparently reduce emissions of formaldehyde from plywood subfloor.

Use of ceiling panels with non-detectable emissions of formaldehyde is predicted to reduce formaldehyde concentrations to very low levels.

Use of Teflon-coated vinyl wall fabric is predicted to reduce concentrations of compounds of concern, acetaldehyde, phenol, DEGBE*, vinyl acetate, 1,2,4-trimethylbenzene and 1-methyl-2-pyrrolidinone.

Formaldehyde concentrations in classrooms with alternative materials are predicted to meet OEHHA REL of 2 ppb when HVAC systems are operating in compliance with ASHRAE 62-1999.

No substantial odor problems are predicted when HVAC systems are operating in compliance with ASHRAE 62-1999.

*Di(ethylene glycol)butyl ether or 2-(2-butoxyethoxy)ethanol 